\title{
Impact of COVID-19 on Pakistani dentists: a nationwide cross sectional study
}

\author{
Ramsha Kamran * ${ }^{*}$, Kiran Saba and Saima Azam
}

\begin{abstract}
Background: The COVID-19 outbreak which developed into a public health crisis has raised concerns regarding infection control among health care workers particularly dentists all over the world. The aim of this survey was to assess awareness, fear and compliance with practice modification according to CDC guidelines during COVID-19 pandemic among Pakistani dentists.

Methods: A cross-sectional study was conducted using an online survey questionnaire. The questionnaire was designed on Google Forms and was distributed among all seven regions of Pakistan through social media and WhatsApp after carrying out the reliability analysis. Statistical analysis was performed using SPSS 20.0. Question wise analysis using frequencies and percentages was done. Pearson correlation and Kruskal Wallis test was applied to check association of awareness level with qualification and workplace setting.

Results: A total of 313 dentists participated and submitted the form online from all regions of Pakistan. The response rate was quite satisfactory as Pakistan was under an official lockdown and most of the hospitals/clinics were either closed or operating with minimum staff. Most of the dentists were well aware of the CDC guidelines. However, $75 \%$ of the dentists were afraid of getting infected and $88 \%$ of them were anxious while providing treatment. Sixty-eight percent of them were avoiding aerosol generating procedures and only $28 \%$ were using rubber dam isolation. Regional analysis was also done and areas of poor compliance were identified. Only 38.5\% dentists in Balochistan were using N95 masks and none of the dentists (0\%) were using rubber dam isolation. A large number of dentists (80.9\%) were afraid and wanted to close their dental practice in Khyber Pakhtunkhwa. Furthermore, a positive correlation was seen between the designation and awareness level $(p=0.01)$. Similarly, significant correlation $(p=0.03)$ was seen between qualification and workplace setting.
\end{abstract}

Conclusion: The results of the study can help devise strategies to ensure adherence with infection control guidelines in regions with poor compliance. Initiation of awareness programs to help overcome fear and train the faculty and staff in the targeted areas would greatly contribute towards reducing the spread of infection and thus lowering the healthcare burden in a third world country like Pakistan.

Keywords: Healthcare, Pakistan, Workplace, Public health, Infection control, Afraid

\section{Background}

The outbreak of coronavirus disease (COVID-19) was observed for the first time in December 2019 [1] and is believed to have originated in a seafood market in

*Correspondence: ramsha_k@outlook.com

Operative Dentistry Department, Islamabad Medical and Dental College,

Main Murree Road, Bharakahu, Islamabad, Pakistan
Wuhan City, China [2]. In January 2020, the World Health Organization (WHO) declared COVID-19 a public health emergency of international concern [3, 4] and within a few months the General Manager of WHO declared COVID-19, a pandemic which has spread all over the world [5]. COVID-19 pandemic is much more than a global health crisis of our time and the biggest 
challenge faced by us since World War II, according to United Nations Development Programme (UNDP) [6].

Coronavirus is thought to have a zoonotic origin [7] and structurally belongs to a single stranded RNA family with a size of $\sim 350$ kilo base-pair (kbp) $[8,9]$.The virus has the ability to cause severe acute respiratory tract infection and is highly contagious, spreading through saliva, hands, nasal droplets and less commonly through surface contact $[10,11]$.

Due to its rapid spread, coronavirus disease has caused wide spread public health concerns as entire international community is in its grip now [7]. A large number of health care workers have reported acquiring the disease while working with infected individuals. According to a note on worker exposure risk to COVID-19, published by Occupational Safety and Health Administration (OSHA), dental professionals fall into very high-risk exposure category for nosocomial infection and can become carriers of the disease due to their routinely aerosol generating procedures [12]. Similarly, an article published by the New York Times on March 2020 entitled "The worker who face the greatest coronavirus risk", described that dentists are the most exposed workers, much more than nurses and general physicians [13]. Dentists therefore should take measures for prevention and entertain a high level of awareness to reduce risk of contagion from COVID-19 [14] and appropriate mitigation of further spread.

In face of current pandemic, anxiety is a normal and predictable response, but severe anxiety can lead to a state of panic leading to irrational behaviour especially in high risk profession like dentists [2]. Although Centers for Disease Control and Prevention (CDC), the American Dental Association (ADA) and WHO have published preventive guidelines to control the spread of COVID-19 [15], majority of dentists are still scared and unwilling to treat patients in this situation. In fact a lot of dentists might not even be aware of these guidelines [2].

In developing countries like Pakistan, it is still a debatable topic whether infection control protocols are religiously followed in dental clinics and OPDs as one of the prime factors influencing it, is finance or resources, reported by Dental News Pakistan on May 2020 [16]. This can be confirmed by a few previous studies showing an overall poor compliance and knowledge on use of personal protective equipments (PPEs) among dental students of a teaching hospital in Rawalpindi, Pakistan [17]. Similar results were seen in Karachi, Pakistan where only $20 \%$ of the respondents were compliant unlike in other countries like Kuwait, New Zealand, Saudi Arabia and Canada where knowledge and compliance was far better (84\%) [18]. Therefore, lack of formal training/knowledge in infection control and limited resources is thought to be the reason of not adhering to cross infection control guidelines [19]. However, such negligence can not be afforded at any cost during this current pandemic as it can have catastrophic results leading to severe economic and healthcare burden in a third world country like Pakistan.

As there is very limited data available on a developing country like Pakistan during COVID-19 pandemic the purpose of this study is to assess the awareness, fear and compliance with the work practice modification among Pakistani dentists.

\section{Methods}

A cross sectional survey was conducted using an online survey questionnaire from 16 to 20th June 2020. Ethical approval was obtained from Institute's Research \& Ethics Committee.

The questionnaire was designed on Google Forms and reliability analysis was undertaken by carrying out a pilot survey initially. The intra-class correlation showed a strong relation of 0.71 . In order to achieve maximum possible outreach in all regions of Pakistan, all central locations of Pakistani practicing dentists were identified on social media and WhatsApp. After identification, the questionnaire was posted on the Pakistan Dental Forum (largest representation of Pakistani dentists on social media), facebook pages of renowned dental colleges across Pakistan and on WhatsApp groups representing the Pakistani Dental Community.

A structured questionnaire was prepared to assess the fear and compliance of Pakistani dentists with work practice modification during the COVID-19 pandemic (Additional file 1: COVID-19 Questionnaire). The questionnaire comprised of 32 closed ended questions of which 6 were about the dentists' demographic information and 8 regarding fear and anxiety assessment during the COVID-19 outbreak. The questions regarding fear and anxiety were adapted from the questionnaire used in study conducted by Ahmed et al. in thirty different countries across the world [2]. Rest of the questions were related to the knowledge and practice modification of dentists in accordance with the updated CDC and ADA practice guidelines.

Data analysis was carried out using Statistical Package for the Social Sciences version 20.0 (SPSS 20.0). Frequencies and percentages were calculated for qualitative variables. Question wise analysis in terms of percentages for each response was done. Association of awareness level with designation/qualification and workplace setting was evaluated using Pearson correlation and Kruskal-wallis $\mathrm{H}$ test respectively. 


\section{Results}

A total of 313 practicing dentists participated and submitted the questionnaire from seven different regions of Pakistan. The response was quite satisfactory as the questionnaire was only filled by dentists who were practicing during the lockdown period and most of the hospitals/ clinic were either closed or operating with minimum staff. The questionnaire comprised of 32 questions in three sections. All questions were mandatory.

Figure 1 shows the distribution of participants' responses by region.

Table 1 shows the demographic information of the participants. Out of 313 participants, $42.81 \%$ were male and $57.19 \%$ were female with a common age bracket of $20-40$ years $(83 \%)$. By designation most of the participants were general practitioners (34\%).

Figure 2 shows the level of fear and anxiety of dental professionals during COVID-19. Most of the dentists were afraid of getting infected with COVID-19 from a patient or a co-worker and were anxious while providing treatment to a suspected patient. Ninety-two percent had the fear that they would carry the infection back to their family.

Figure 3 shows the knowledge and work practice modification of dental professionals about COVID-19. Majority of the of the dentists were taking patients' history of fever, cough and body aches before performing dental treatment, $68 \%$ of the dentists were trying to avoid aerosol generating procedures whenever possible and prioritising minimally invasive dentistry. Most of the dentists were well aware of the CDC guidelines related to PPEs against the COVID-19 in their dental practice. Surprisingly, a very small number of dentists (28\%) were using rubber dam isolation while performing aerosol generating procedures.

Regional variations were also noted in the level of awareness among the practicing dentists across Pakistan. In Balochistan, only $46.2 \%$ of the dentists were taking travel history, 38.5\% were wearing N95 masks while treating a patient and $53.8 \%$ were using eye protection. None of the dentists $(0 \%)$ were using rubber dam isolation, $15.4 \%$ were using high volume suction during dental treatment and asking the patient to rinse their mouth with an anti-bacterial mouth wash before treatment.

A large number of dentists (80.9\%) in Khyber Pakhtunkhwa, wanted to close their dental practice until the number of COVID-19 cases start declining.

Association of awareness level with designation/qualification and workplace setting (private, government setup) was also evaluated. The correlation between the designation and awareness level was significant with a $\mathrm{p}$ value of 0.01 , showing that the awareness level rises with rise in qualification. Similarly, a significant correlation was seen with work place setting and awareness level with a $\mathrm{p}$ value of 0.031 , indicating that the doctors of private hospitals have more mean awareness score as compare to the ones working in government setup.

\section{Discussion}

This is the first nationwide study that has been undertaken in Pakistan which looked into the fear and anxiety levels and also assessed dentists' knowledge and practice modification (according to $\mathrm{CDC}$, WHO, ADA guidelines)

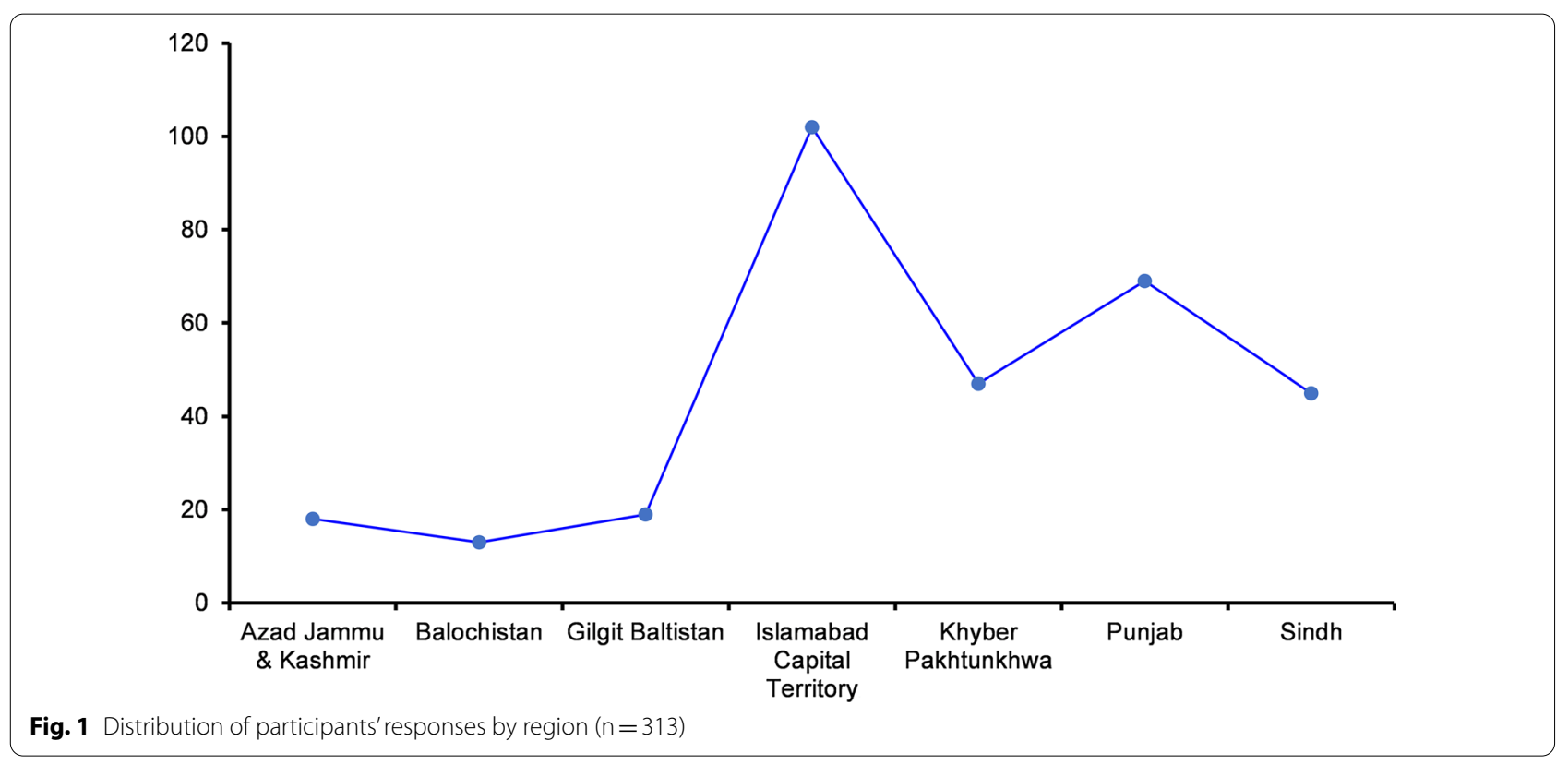


Table 1 Demographic information of dental care professionals $n=313$

\begin{tabular}{lc}
\hline Demographics & Numbers (\%) \\
\hline Gender & $134(43)$ \\
Male & $179(57)$ \\
Female & \\
Age & $181(58)$ \\
$20-30$ years & $77(25)$ \\
$31-40$ years & $34(11)$ \\
$41-50$ years & $21(7)$ \\
50 years and above & \\
Qualification/designation & $64(20)$ \\
House officer & $107(34)$ \\
General practitioner & $70(22)$ \\
Postgraduate trainee & $72(23)$ \\
Consultant/specialist & \\
Which practice do you workin? & $97(31)$ \\
Government & $113(36)$ \\
Private hospital & $103(33)$ \\
Clinic &
\end{tabular}

during the current pandemic. A survey conducted in 2012 showed that out of 13,000 dentists registered in Pakistan, only 8500 of them were actually working. However, the current study revealed that only 313 dentists across Pakistan participated and submitted the form. This low number depicts that most of the dentists were not working during the COVID-19 era, as the questionnaire was only to be filled by practicing dentists during that time. This could be due to the lockdown situation in the country or because the dentists were actually afraid to practice during that time.

In situations like the ongoing pandemic with increasing mortality rate, fear and anxiety are natural psychological implications [2]. The fear of getting infected while treating a patient or carrying the infection back home has been reported as a factor causing psychological trauma in healthcare workers $[20,21]$. The current study revealed that a large number of dentists (75\%) were afraid of getting infected in the workplace and even a larger number $(92 \%)$ were afraid to carry the infection back home. Similar results were observed by a Turkish study which reported that $90 \%$ of the dentists were afraid of getting infected and $95 \%$ of them were concerned about carrying the virus to their family [1].

Taking patients history is very important specially during this ongoing pandemic since a COVID infected patient with acute symptoms is a potential source of infection. In the current study, 93\% of the dentists in Pakistan were taking patients history of COVID-19 symptoms and $68 \%$ of them were avoiding aerosol generating procedures.

Dentists have always been at higher risk for airborne infections, therefore they should be even more cautious while attending patients during this current pandemic. Use of face shields and goggles is recommended to prevent spatter during a dental procedure. In Pakistan most of the dentists were well aware of the CDC guidelines regarding the use of PPEs (eyewear $80 \%$, face shield $82 \%$ and protective clothing $73 \%$ ). Surprisingly $69 \%$ of the

\begin{tabular}{|c|c|c|c|c|c|c|}
\hline \multirow[b]{2}{*}{ Fear of getting infected } & - Yes & $\square$ No & \multicolumn{4}{|l|}{ - Unaware } \\
\hline & & & $75 \%$ & & $12 \%$ & $13 \%$ \\
\hline Anxious when treating suspected COVID-19 patient & \multicolumn{4}{|c|}{$88 \%$} & & $5 \% \quad 7 \%$ \\
\hline \multirow[t]{2}{*}{ Want to close dental practice during COVID-19 crisis } & \multicolumn{3}{|c|}{$53 \%$} & $25 \%$ & \multicolumn{2}{|r|}{$22 \%$} \\
\hline & \multicolumn{4}{|c|}{$92 \%$} & \multicolumn{2}{|r|}{$3 \% 5 \%$} \\
\hline Fear of getting quarantined & \multicolumn{2}{|c|}{$41 \%$} & \multicolumn{2}{|r|}{$42 \%$} & \multicolumn{2}{|r|}{$17 \%$} \\
\hline Anxious about the COVID-19 treatment cost & \multicolumn{3}{|c|}{$54 \%$} & \multicolumn{2}{|l|}{$31 \%$} & $15 \%$ \\
\hline
\end{tabular}

Fig. 2 Fear and anxiety assessment of dental professionals 


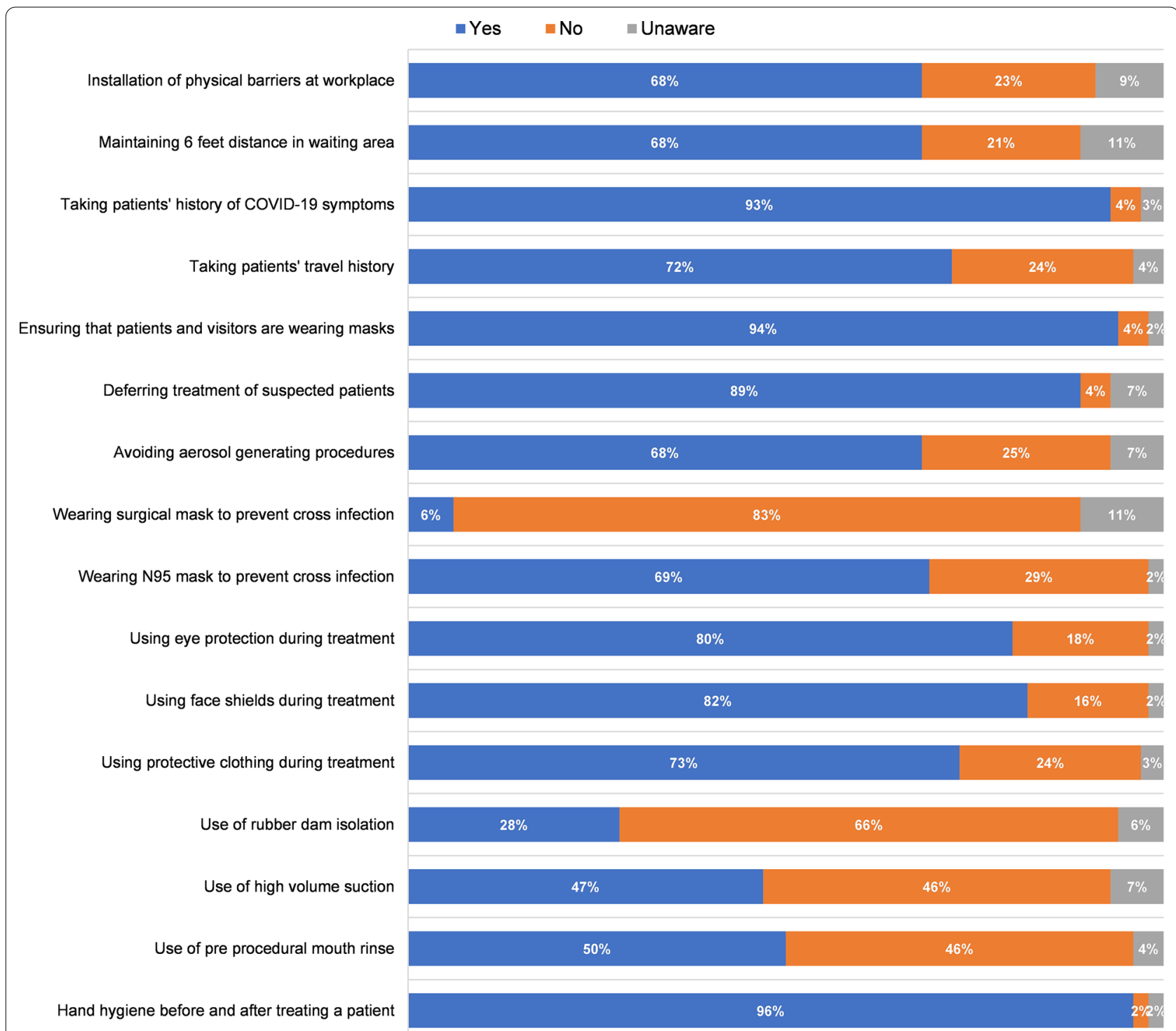

Fig. 3 Knowledge and practice modification of Dentists during COVID-19

dentists were using N95 masks while treating patients compared to only $12.36 \%$ Turkish dentists [1]. This high percentage may be because Pakistan being a third world country has received a lot of foreign aid during this time.

Dental dams have been recommended by CDC to minimise droplet spatter and aerosols especially during the COVID-19 pandemic. The current study revealed that only $28 \%$ of the dentists were using rubber dam isolation for aerosol generating procedures compared to $13.84 \%$ Turkish dentists [1]. This low percentage is because a lot of dentists find it difficult and time consuming using rubber dam on every patient. Regarding the use of rubber dam similar responses (14\%) were seen in a survey conducted in 30 different countries [2].
According to CDC guidelines there is no published evidence regarding the clinical effectiveness of pre procedural mouth rinses (PPMRs) but they suggest its use to reduce the level of oral microorganisms in aerosols generated during dental procedure. Ahmed et al. reported $24 \%$ of the dentists were using pre procedural mouth rinse in different countries across the world [2], whereas in our study $50 \%$ of the Pakistani dentists were using mouth rinse before the procedure.

In the present study data was collected from different regions of Pakistan. Regional differences were also noted regarding the awareness in practice modification. In Balochistan lack of adherence to the CDC guidelines was noted as discussed in the results. This may 
be because of the distant nature and security situation in this region that the healthcare professionals are deprived of essential information and equipment [22].

One of the significant findings of our study was a positive correlation between awareness level and qualification/designation and workplace setting, showing that the awareness level rises with the rise in qualification/ designation of the doctor. Similarly, the doctors of private hospitals have more mean awareness score as compare to the doctors of government setup. The major reason for this correlation is that private hospitals have always worked on maintaining their good repute by constituting and adhering to cross infection protocols and strict supervision, as they are adequately funded to achieve the patients trust and satisfaction.

One of the limitations of our study was that very few dentists were practicing during the pandemic and so a low response was obtained which can affect the generalizability of the study. Another limitation was that we could not get equal representation from all the regions of Pakistan. Only 13 dentists from Balochistan filled and submitted the questionnaire. Therefore, due to the limited data from this region, the results should be carefully interpreted.

\section{Conclusion}

This study provides valuable data for developing strategies to overcome fear and spread awareness among Pakistani dentists, especially to the respective regions with poor compliance, to adhere to the current infection control guidelines. This will help contain the spread of disease and can eventually help lower the healthcare burden in a third world country like Pakistan.

\section{Supplementary Information}

The online version contains supplementary material available at https://doi. org/10.1186/s12903-021-01413-6.

Additional file 1: Questionnaire used to assess the fear and compliance of Pakistani dentists with work practice modification during the COVID-19 pandemic

\section{Abbreviations}

ADA: American Dental Association; CDC: Centers for Disease Control and Prevention; COVID-19: Coronavirus disease 2019; OPD: Out patient department; OSHA: Occupational Safety and Health Administration; PPE: Personal protective equipments; PPMR: Preprocedural mouth rinses; SPSS: Statistical Package for the Social Sciences; UNDP: United Nations Development Programme; WHO: World Health Organization.

\section{Acknowledgements}

We want to thank all the faculty of Islamabad Medical and Dental College for their support.

\section{Authors' contributions}

RK contributed to conception, design, data acquisition, analysis and interpretation, drafted and critically revised the manuscript; KS contributed to data acquisition, interpretation and manuscript revision; SA contributed to data acquisition and critically revised the manuscript. All authors read and approved the final manuscript.

Funding

No funding was obtained for the study.

\section{Availability of data and materials}

The datasets used and/or analysed during the current study are available from the corresponding author on reasonable request.

\section{Ethical approval and consent to participate.}

Ethical approval was obtained from Islamabad Medical and Dental College's Research \& Ethics Committee (Ref \# IMDC/DS/IRB/164). All participants filled out the questionnaire on Google Forms with their consent. Participants had to answer a yes/no question to confirm their willingness to participate voluntarily. The method of obtaining written consent was approved by the Ethics Committee.

\section{Consent for publication \\ Not applicable.}

\section{Competing interests}

The authors declare that they have no competing interests.

Received: 19 August 2020 Accepted: 26 January 2021

Published online: 10 February 2021

\section{References}

1. Duruk G, Gumusboga ZS, Colak C. Investigation of Turkish dentists' clinical attitudes and behaviors towards the COVID-19 pandemic: a survey study. Braz Oral Res. 2020;34:e054.

2. Ahmed MA, Jouhar R, Ahmed N, Adnan S, Aftab M, Zafar MS, et al. Fear and practice modifications among dentists to combat novel coronavirus disease (COVID-19) outbreak. Int J Environ Res Public Health. 2020;17(8):2821.

3. World Health Organization. Statement on the second meeting of the International Health Regulations (2005) Emergency Committee regarding the outbreak of novel coronavirus (2019-nCoV. Geneva, Switzerland. Published 2020. https://www.who.int/news-room/detail/30-01-2020-state ment-on-the-second-meeting-of-the-international-health-regulation s-(2005)-emergency-committee-regarding-the-outbreak-of-novel-coron avirus-(2019-ncov). Accessed 14 June 2020.

4. World Health Organization. WHO Director-General's opening remarks at the media briefing on COVID-19. Published 2020. https://www.who.int/ $\mathrm{dg} /$ speeches/detail/who-director-general-s-opening-remarks-at-themedia-briefing-on-covid-19---11-march-2020. Accessed 14 June 2020.

5. Peditto M, Scapellato S, Marcianò A, Costa P, Oteri G. Dentistry during the COVID-19 epidemic: an Italian workflow for the management of dental practice. Int J Environ Res Public Health. 2020;17(9):3325.

6. Coronavirus disease COVID-19 pandemic | UNDP [Internet]. UNDP. Published 2020. https://www.undp.org/content/undp/en/home/covid -19-pandemic-response.html. Accessed 14 June 2020.

7. Ather A, Patel B, Ruparel NB, Diogenes A, Hargreaves KM. Coronavirus Disease 19 (COVID-19): implications for clinical dental care. J Endod. 2020;46(5):584-95.

8. Coronaviridae Study Group of the International Committee on Taxonomy of $\mathrm{V}$. The species Severe acute respiratory syndrome-related coronavirus: classifying 2019-nCoV and naming it SARS-CoV-2. Nat Microbiol. 2020;5(4):536-44.

9. Chen Y, Liu Q, Guo D. Emerging coronaviruses: genome structure, replication, and pathogenesis. J Med Virol. 2020;92(4):418-23.

10. Khurshid Z, Asiri FYI, AI WH. Human saliva: non-invasive fluid for detecting novel coronavirus (2019-nCoV). Int J Environ Res Public Health. 2020;17(7):2225.

11. Peng X, XuX, LiY, Cheng L, Zhou X, Ren B. Transmission routes of 2019nCoV and controls in dental practice. Int J Oral Sci. 2020;12(1):9. 
12. Occupational Safety and Health Administration Official Website. Worker exposure risk to COVID-19. Published 2020. https://www.osha.gov/Publi cations/OSHA3993.pdf. Accessed 14 June 2020.

13. Gamio L. The workers who face the greatest coronavirus risk. The New York Times. Published 2020. https://www.nytimes.com/interactiv e/2020/03/15/business/economy/coronavirus-worker-risk.html. Accessed 14 June 2020

14. Sabino-Silva R, Jardim ACG, Siqueira WL. Coronavirus COVID-19 impacts to dentistry and potential salivary diagnosis. Clin Oral Investig. 2020;24(4):1619-21.

15. Khader Y, Al Nsour M, Al-Batayneh OB, Saadeh R, Bashier H, Alfaqih M, et al. Dentists' awareness, perception, and attitude regarding COVID-19 and infection control: cross-sectional study among Jordanian dentists. JMIR Public Health Surveill. 2020;6(2):e18798.

16. Infection control in dentistry: present and future. Dental News Pakistan Published 2020. https://www.dentalnewspk.com/infection-control-indentistry-present-and-future/. Accessed 14 June 2020.

17. Qamar MK, Shaikh BT, Afzal A. What do the dental students know about infection control? A cross-sectional study in a teaching hospital, Rawalpindi, Pakistan. BioMed Res Int. 2020:2020:1-5.

18. Das G, Samejo I, Ahmed S, Jabeen B, Shaikh MI, Mushtaque K. Cross infection control in private dental practice in Karachi, Sindh. Prof Med J. 2019;26(08):1354-8.
19. Ahmed $\mathrm{H}$. Methods of sterilization and monitoring of sterilization across selected dental practices in Karachi, Pakistan. J Coll Phys Surg Pak. 2015:25(10):713-6.

20. Tam CW, Pang EP, Lam LC, Chiu HF. Severe acute respiratory syndrome (SARS) in Hong Kong in 2003: stress and psychological impact among frontline healthcare workers. Psychol Med. 2004;34(7):1197-204.

21. McAlonan GM, Lee AM, Cheung V, Cheung C, Tsang KW, Sham PC, et al. Immediate sustained psychological impact of an emerging infectious disease outbreak on health care workers. Can J Psychiatry. 2007;52(4):241-7.

22. Balochistan's Inspirational Efforts for Dental Training and Recognition. Dental News. Published 2020. https://www.dentalnewspk.com/ balochistans-inspirational-efforts-for-dental-training-and-recognition/. Accessed 14 June 2020

\section{Publisher's Note}

Springer Nature remains neutral with regard to jurisdictional claims in published maps and institutional affiliations.
Ready to submit your research? Choose BMC and benefit from:

- fast, convenient online submission

- thorough peer review by experienced researchers in your field

- rapid publication on acceptance

- support for research data, including large and complex data types

- gold Open Access which fosters wider collaboration and increased citations

- maximum visibility for your research: over $100 \mathrm{M}$ website views per year

At BMC, research is always in progress.

Learn more biomedcentral.com/submissions 